\title{
Industry Revolution IR 4.0: Future Opportunities and Challenges in Construction Industry
}

\author{
Wesam S Alaloul ${ }^{1, *}$, Mohd Shahir Liew ${ }^{1}$, Noor Amila Wan Abdullah Zawawi ${ }^{1}$, and Bashar S Mohammed ${ }^{1}$ \\ ${ }^{1}$ Civil and Environmental Engineering Department, Universiti Teknologi PETRONAS, 32610 Seri Iskandar, Perak, Malaysia.
}

\begin{abstract}
The future of construction industry development is the approach of the componentindustrialization, the construction-breakdown, design-identical, construction-assembled, operation-data technique to maximize the life cycle value. This paper presents a general idea of Industrial Revolution (IR) 4.0 with the introduction descriptions of important aspects in Construction Industry (CI) development. The aim is to define and show possible research areas connected with the IR 4.0 into the CI. For this purpose, an analysis was made, based on the most recent literature, to point out actual needs in the CI in terms of its evolution into IR 4.0 level. It is shown that multidiscipline approaches are not investigated to create special rules, procedures and methods and know-how designed for introducing the principles of IR 4.0 in the CI. A popular from stakeholders in the CI understand how digitization is affecting each part of their trade, however, its practical applications are still in infancy stage. IR 4.0 concepts should be combined with construction production, novel expertise must be applied to the intellectual engineering of modern construction, enhance the level of incorporation, to achieve the sustainable development.
\end{abstract}

\section{Introduction}

Construction is a wide flat industry, supporting all other industries significantly, where value formation practically happens in the sense of facilities or assets development. Construction personnel allocates only around $30 \%$ of their functioning time to their main task. The residual $70 \%$ is occupied by consecutive errands, moving ingredients, arranging up, reorganizing the building site and observing resources and equipment. The construction industry is on the border of an innovative industrial era $[1,2]$. A significant change occurs in the construction industry with the appearance of the fourth industrial revolution or IR 4.0 which will convert the construction industry in the direction of further digitally developed trades. The notion of creating a "digital twin" of a building or a piece of infrastructure is central to enables accurate, well-informed decisions to be made throughout the project lifecycle. IR 4.0 is still in its very early stages and the construction sector still lags significantly behind other industries in terms of the automation of processes and the level of digitalization [3, 4]. Consequently, efficiency has decayed during the previous years, or else in some circumstances, even dropped. The future of construction industry will get production schemes with further intelligent via apply of digital schemes. In the meantime, there will be further knowledge-oriented projects and thoughtful species projects that will significantly enhance construction industry effectiveness and affordability $[5,6]$.

Digitalization of suitable data, a fast answer for solving the problem and cooperative working context in the projects scheme design, building/construction and operation, utilization of resources and enhance quality and safety. This will revolutionize not only how physical structures are designed, built and maintained, but also how they are subsequently used [2, 7, 8]. Take into consideration the quick advent of "augmented reality, drones, $3 D$ scanning and printing, Building Information Modelling (BIM), autonomous equipment and advanced building materials" altogether have nowadays touched market ripeness. During the first three industrial revolutions, mechanical, electrical and information technology had produced, which were intended for enhancing the productivity of business procedures [9]. The initial industrial revolution enhanced productivity via the use of hydropower, better applying of steam power and improvement of machine tools; the second industrial revolution introduced electricity and bulk production; the third industrial revolution more enhanced automation by means of electronics and information technology. Currently the fourth industrial revolution is coming into view that is directed by Cyber Physics System (CPS) approach to amalgamate the physical world with the information era for future industrial improvement $[4,10]$.

It is conceivable to designate three future-related themes linked to IR 4.0 for instance: a transaction with complexity, capability for novelty and elasticity. Furthermore, it is probable to originate six design concepts from its ingredient: "interoperability, virtualization, decentralization, real-time capability, service orientation, and modularity". Interoperability guarantees the linking and communication amongst physical ingredient, individuals, and smart units, while virtualization is understood as the simulated duplicate of physical items. Because of the decentralization and real-

\footnotetext{
* Corresponding author: wesam.alaloul@utp.edu.my
} 
time competence, the ingredient is permitted to decide on their own based on the compiled and analysed the data immediately $[3,11,12]$.

The current study shows a vital theoretical contribution to the sympathetic of IR 4.0 influence and challenges in the construction industry. The results are based on the appraisal and review of the available literature. The aim of this study is to analyses current knowledge connected with the introducing of IR 4.0 concept into construction industry with the special focus on its reflections on the industry future. The analysis was performed based on the most popular articles published in journals during the last decade which showing the actual change of interest in this filed, taking into account possibility of usage of this concept in the construction industry. In this movement, industrialization of construction industry progress in the forthcoming is discussed. A novel production arrangement of construction industrialization, that is BIM technology oriented, is set forward. New technologies and ideas related to this concept need to be further investigated to make it possible to use them in the construction industry by increase the information accessibility and transferability $[2,13,14]$.

\section{Literature Review}

\subsection{Industry revolutions IR 4.0}

The industry has override complete three former revaluations, each of them with a reflective influence on its practices and productiveness. Steam power was the transformative energy during the nineteenth and electricity appeared more in the twentieth, earlier the significant computerization started the third important change. In the twenty-first century, the industry will accomplish IR 4.0 epoch with intellect as its essential. IR 4.0 is described by a fusion of skills which is blurring the lines between the physical, digital, and biological scopes $[15,16]$. The key concepts of IR 4.0 were issued for the first time in 2011, as shown in Figure 1. It will convert the industry as profoundly and irrevocably as each of its three predecessors, and more rapidly than any of them. In spite of the excessive attention to the perception of IR 4.0 universal, there is no one officially description for it. However, it can be defined as "the integration of complex physical machinery and devices with networked sensors and software, used to predict, control and plan for better business and societal outcomes", or "a new level of value chain organization and management across the lifecycle of products" $[17,18]$.

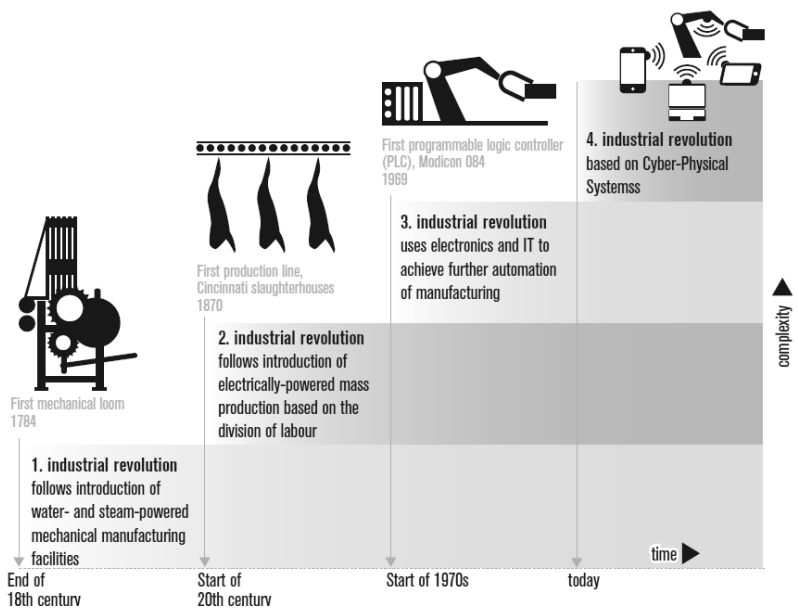

Fig. 1. The four stages of industrial revolution.

The four main ingredients of IR 4.0 are; CPS (links among the physical and cybernetic domain), the IoT, the IoS, and the intelligent units. However, machine communications (M2M) and intelligent products are not deliberated as selfgoverning portions. The M2M is a part of the IoT and intelligent products are a sub-ingredient of the CPS. The productivity achieved via the usage of intelligent technologies can assist in provide jobs and increase user request with extra revenue (compensation influence), nonetheless, the usage of novel production technologies and procedures can also abolish some current jobs (redundancy influence). There are concerns that the redundancy effect from IR 4.0 will predominate in the long run, leading to what is known as technological unemployment $[19,20]$.

\subsection{Construction industry and digitalization}

The construction industry significantly impacts the economy, surroundings, and civilization as a whole. It will remain to define the day-to-day lives in different ways since houses, offices and the transportation modes are all parts of the built 
environment. Construction projects became continually further complex, budget and schedule weights are increasing while quality potentials growing. Contrasted with numerous different industries, the construction industry has usually been late in technological progress. Consequently, the industry improvements have been insufficient and continued almost flat for the previous 5 decades. Personnel in the construction businesses depend deeply on specific skills, particular practice, technology preparation, and judgment based on experience which are enormously challenging to be automated.

Recent research has revealed that the construction industry has failed to keep pace with productivity improvements seen in the manufacturing sector over the last 20 years $[2,3,12]$. The gap between construction and manufacturing industry is principally extensive: Manufacturing has gotten productivity increase by $34.1 \%$ over the previous decade, in contradiction of an achievement of $27.1 \%$ for the entire of the other sectors. Even though construction industry and manufacturing industry have its place in two dissimilar groups, both of them are extremely reliant on each other. Construction industry could even be considered as an unusual case of manufacturing industry in the light of development idea of construction industrialization. The potential of digitization in the construction industry is rated across individual divisions, departments and functions, it can be classified into four main groups: "digital data, digital access, automation, and connectivity". Digital data covers the electronic gathering and processing of data to get new and current perceptions into each relation in the value chain and after that place these current perceptions to better usage. Automation cluster composed of the innovative technologies which generate autonomous and self-arranging schemes $[4,11]$. Digital access describes the possible logical by mobile contact to the internet and local networks. Finally, connectivity discovers the potentials to link up and synchronize previously discrete tasks. For stakeholders in the construction industry, the value chain can be broken down into the succeeding associations: Procurement and materials account for a great mass of entire budget in the construction projects. Digital platforms assistance maintains the budget low. Electronic procurement allows budget re-education of about $5 \%$ for paper-based rebuying and about $10 \%$ in the situation of online auctions $[6,8,21]$.

\subsection{BIM in digitized construction industry}

Building Information Modeling (BIM) is a technology which defines an engineering project containing intellectual objects with their specific data possessions and consideration instructions, therefore every object's representation and its inside ingredients and characteristics available to be presented. BIM has five main characteristics; "visualization, coordination, simulation, optimization, the ability to plot". The great benefit of BIM is the digital simulation and modeling of the project which is generated earlier from the first task in the project to become a real. Consequently, BIM reduces planning faults, provide fast calculations, quantifies further costs and displays replacements [22, 23]. Hence, BIM with its various digital tools and practices can significantly enhance the workability of the construction industry. IR 4.0 provides a huge scope to progress and establish a new standard for what is achievable and digital data. BIM will accelerate this advancement by making an effort to form a central storehouse to gather digital information regarding a project or asset. By processing the completed, truthful data through all stages of a project lifecycle changing from design to construction and conservation, schedule and budget effectiveness should be improved and faults could be reduced considerably $[24,25]$. By implementing BIM at a preliminary stage of the project, the advantages of digital data can be achieved. BIM technology is implemented in preparation for construction industrialization. Based on the three-dimensional visualization dimensions, BIM provides time, cost and sustainability aspects to it and forms a $6 \mathrm{D}$ model, that assistance in deciding of the choice and usage of assembled parts. Thus, not only quality and time are ensured, however, decrease waste and enhance the general project performance too. In the construction phase, BIM technology and Augmented Reality (AR) will work together to provide digital data to physical parts. Additionally, combined and compatible using of BIM technology and digital processing appreciate well-organized formation, advanced management and precise distribution of information [26-28].

For providers of prefabricated parts, BIM technology offers exact useful information to enhance the combination of manufacturer's design, fabrication, construction, and conservation procedure. The information in the BIM simulation transfers the usage of prefabricated parts in the construction procedure to a very appropriate. The digital documentation needed by BIM will increase the size of resultant data for each part. In this sense, construction stakeholders have to be capable to handle the resultant overflow of data. processing this data and placing it into profitable usage will permit the stakeholders to achieve the complete potential of this improvement, which will lead to novel business in a digitalized context $[11,14,29,30]$.

Obviously, the construction industry is conscious of the transformation significant in the direction of digitization and IR 4.0. Digitization provides the stakeholders approaches to enhance the efficiency. Even though other industries are previously benefiting along the complete value chain construction industry still lags behind. A small number of stakeholders have yet transferred to the latent of digitization as an approach to enhance their performance and productivity.

\section{Discussion of construction industry future in IR 4.0}

Construction industry should provide the nation with homes along with transportation and effectiveness substructure. To overcome this challenge, the industry is virtually underneath an ethical responsibility to convert to IR 4.0. Its 
transformation will have significant effects by decreasing construction budget; on the environment, by optimizing the use of limited materials or by constructing facilities supplementary eco-effectual. Although all other industries have undertaken incredible variations during the previous years, and have gained the advantages of technology, the construction industry has been uncertain about fully embracing the modern technological chances, and its labor efficiency has deteriorated accordingly. In fact, the construction industry has enormous potential for enhancing effectiveness, obligations to digitalization, pioneering technologies and modern construction methods [3, 10, 31].

In smart construction projects, there will be not just personnel and computer contact, however, things-to-things contact too, that targets to generate improved outcomes to satisfy stakeholders' requirements. The consideration must be given to three kinds of combination: "horizontal, vertical and end-to-end". Horizontal combination mentions to a peer group of value-creation systems including integration of dissimilar mediators like business associates and clients, while, vertical interacting interests in smart construction schemes as replacements to traditional static construction procedures. End-to-end integration is directed through the whole value chain to gain on product design, construction, and the user. IR 4.0 is almost begun and will have a significant effect on the construction industry future since it characterizes growth on three points. (1) Digitization of production: data schemes for organization and construction preparation; (2) Automation: schemes for information gaining from the construction site and further machines usage; (3) Linking construction sites to a supply chain: comprehensive automatic information exchange. The main technologies empowering construction industry conversion are shown in Figure 2 and discussed as follows [9, 25, 28]. The usage of big data and analytics: procedures produce novel understandings based on the enormous data pools produced during planning, construction and the operations stage of the current facility. Novel procedures of simulation and virtual reality assistance to recognize interdependencies and clashes (clash detection) through the design and engineering phases, and permit a virtual practice of the facility even in the initial design stage. By developing mobile connectivity and augmented reality, stakeholders could involve and contact in a real-time statement and give personnel with further onsite instructions and information. In the top of that cloud computing of BIM will provide all the stakeholders with full access to the enter facility information. 3D scanners construct digital models of current facilities to be integrated with the proposed project. Unmanned aerial vehicles (drones) and embedded sensors could also notice any conventionalities very fast during the construction process and permit deformation monitoring. At the same time, all of the collected information will send in real time to cloud and can be accessed by all the stakeholders for their corrective actions if needed [4].

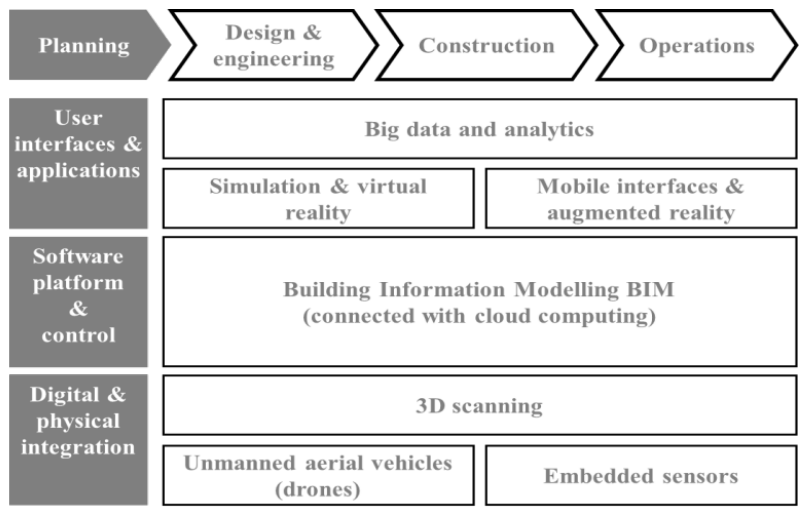

Fig. 2. Digital Technologies Applied in the E\&C Value Chain.

The construction industry must have a strategic plan for the systematic movement in the direction of IR 4.0 at several levels. A complete approach is delineated in the construction industry transformation framework presented in Figure 3. The framework assemblies the different regions and levels of activity based on accountability. Firstly, the alteration depends on the creativities of separate firms, the implementation of novel technologies and procedures, business-model improvement, modifications to the business culture and association. Productivity in construction could obtain a considerable improvement from standardization, modularization, and prefabrication. The standardization of works gives several welfares, e.g. costs reduction, less interface and tolerance problems, better certainty over outcomes [7, 10]. Modularization enhances the benefits of standardization, via possibilities for customization and flexibility. A single and discrete action is not adequate. In construction industry which is highly fragmented and horizontal, several difficulties and obstacles should be handled cooperatively, so the industry as entire has the accountability. It requests to launch novel systems of cooperation or to enhance the present systems. Lastly, governments, also, have a great role to do, in its dual role as a decision maker, regulator, and client $[8,18,23]$. 


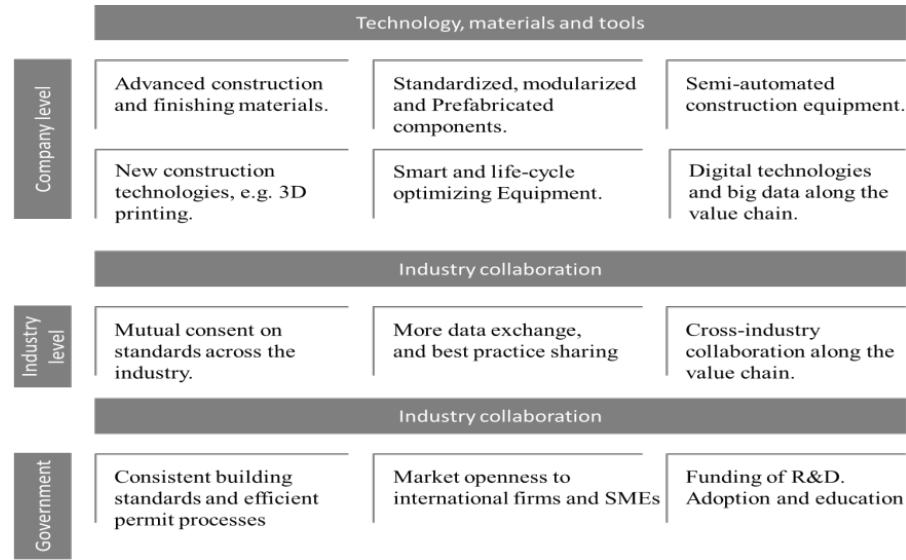

Fig. 3. Industry transformation proposed framework.

The proposed conceptual framework heightened seven planning intentions approaching the implementations of IR 4.0, as following: (1) Standardization of schemes and building a reference architecture, (2) Effective management, (3) Launch of a complete and reliable industrial broadband substructure, (4) Information safety and security, (5) Organization and strategy of work, (6) Personal training and ongoing proficient improvement, and (7) Enhancing the effectiveness of resource usage. Those seven planning intentions are considered as the areas where digital technology could benefit. Likewise, smart associated construction equipment enhances operation ability for labors. Project schedules will adjust themselves automatically according to the availability of labor. In the event of an absence, a task will be transferred to the best qualified for that job. Therefore, engineering decision-making will be supported through verifying the design and during implementation phases of a project and using data from past projects to provide advice. This means engineers will be able to make evidence-based decisions with a high degree of certainty [11, 17]. Consequently, the combination of BIM and construction industrialization is applying benefits of BIM and construction industrialization, instead of just uniting the concepts. In this manner, obstacles in the application of construction industrialization are overcome. It is the indorsing growth of construction industrialization and then permits novel construction industry to appreciate the objectives of high effectiveness economy, environmental protection, and sustainable improvement $[6,9,24]$.

Regarding skill and technology obstacles, such as the improvement of smart devices, big data analysis and analysis, and digital construction. More discussion about those kinds of challenges are presented as follows: The development of smart devices: dissimilar units require dissimilar smart device formations, and smart device fabrication needs ample time and high cost. The construction of the network environment: Building the CPS platform is a multifaceted mission which is presently limited by various circumstances, including the following four aspects. 1) Collaboration between dissimilar systems, 2) CPS modeling and model combination, 3) The combination of CPS, and 4) Verification and testing of CPS. So, it is essential to create a cooperative model for the physical system and the information network system for qualitative and quantitative analysis. The CPS requests full rigorous validation and testing earlier real implementation so as to meet various demands. But, there are no identical standards for verification and testing of the CPS. Big data analysis and processing: most of the parts in IR 4.0, involving the equipment, machines, construction, operations, and services will remain produce data that by nature is big and complex [24]. Digital manufacturing, numerous technologies, management, standards, and other difficulties will be encountered during the execution stage. As the digital world and the physical world are integrated, network security matters are becoming progressively serious. Changing the types of jobs on offer: gradually more increase various socioeconomic debates. Most projections foresee the loss of unskilled jobs. However, there will be substantial demand for "new jobs" posts such as "industrial data scientists" and "robot coordinators" will become commonplace [11, 13, 25].

\section{Conclusion}

Although construction industry is the engine of any economy, its performance can be enhanced through the IR 4.0 involvement, similar to the manufacturing industry. This study seeks to identify the progress made in the construction industry in support of IR 4.0 and digitalization. The development and deployment of other technologies supporting the success to date are pushing towards IR 4.0. The study provides clear evidence that construction industry is doing more than its bit, generating and championing the use of those digital methodologies. At the same time, IR 4.0 introduces some implications for the construction industry. Particularly over the last three years, the use of digital techniques in design and construction has started to mature and even become the norm for many companies. BIM has led the way in digitalization of the construction industry over recent years. It has been clear that there is a significant difference 
between how building designs are assessed to demonstrate compliance in the virtual world, and how buildings perform in the physical world, known as the performance gap. Industry, government, and academia will all have roles to play in meeting that challenge a rethinking of what is desired to prepare the new generation for the future jobs.

\section{References}

1. W.S. Alaloul, M.S. Liew, and N.A.W.A. Zawawi, Identification of coordination factors affecting building projects performance. Alexandria Engineering Journal, 2016. 55(3): p. 2689-2698.

2. A.M. Blayse and K. Manley, Key influences on construction innovation. Construction innovation, 2004. 4(3): p. 143-154.

3. R. Greenwood, R. Suddaby, and C.R. Hinings, Theorizing change: The role of professional associations in the transformation of institutionalized fields. Academy of management journal, 2002. 45(1): p. 58-80.

4. O. Ortiz, F. Castells, and G. Sonnemann, Sustainability in the construction industry: A review of recent developments based on LCA. Construction and Building Materials, 2009. 23(1): p. 28-39.

5. W.S. Alaloul, M.S. Liew, and N.A.W.A. Zawawi. The characteristics of coordination process in construction projects. in Technology Management and Emerging Technologies (ISTMET), 2015 International Symposium on. 2015. IEEE.

6. E.S. Slaughter, Models of construction innovation. Journal of Construction Engineering and management, 1998. 124(3): p. 226-231.

7. T.D. Oesterreich, F. Teuteberg, Understanding the implications of digitisation and automation in the context of Industry 4.0: A triangulation approach and elements of a research agenda for the construction industry. Computers in Industry, 2016. 83: p. 121-139.

8. C. Shang, et al., Study on the standard system of the application of information technology in China's construction industry. Automation in construction, 2004. 13(5): p. 591-596.

9. R. Tulenheimo, Challenges of implementing new technologies in the world of BIM-Case study from construction engineering industry in Finland. Procedia Economics and Finance, 2015. 21: p. 469-477.

10. Z.A. Memon, M.Z.A. Majid, and M. Mustaffar, An automatic project progress monitoring model by integrating auto CAD and digital photos, in Computing in Civil Engineering (2005). 2005. p. 1-13.

11. I. Perkins and M. Skitmore, Three-dimensional printing in the construction industry: A review. International Journal of Construction Management, 2015. 15(1): p. 1-9.

12. L.S. Chan, D.K. Chiu, and P.C. Hung. E-tendering with web services: a case study on the tendering process of building construction. in Services Computing, 2007. SCC 2007. IEEE International Conference on. 2007. IEEE.

13. C.-N. Huang, D. Wu, and M.-T. Wang. An Application of Auto-Identification System in Steel Structural Construction Process. in The 21th International Symposium on Automation and Robotics in Construction. ISARC. 2004.

14. R. Liu and V.C. Chua, Theoretical Digitalization of Information Flow in the Construction Supply Chain. International Journal of Management Research and Business Strategy, 5 (1), 10, 2016. 27.

15. A.A.F. Saldivar, et al. Industry 4.0 with cyber-physical integration: A design and manufacture perspective. in Automation and computing (icac), 201521 st international conference on. 2015. IEEE.

16. J. Wan, H. Cai, and K. Zhou. Industrie 4.0: enabling technologies. in Intelligent Computing and Internet of Things (ICIT), 2014 International Conference on. 2015. IEEE. 
17. N. Kudriashov et al., Implementation of cloud services for advance management of steel transport for continuous casting production. Annals of DAAAM \& Proceedings, 2016: p. 457-463.

18. M. Mazzucato and M. Tancioni, Innovation and idiosyncratic risk: an industry-and firm-level analysis. Industrial and Corporate Change, 2008. 17(4): p. 779-811.

19. L. Wang and G. Wang, Big data in cyber-physical systems, digital manufacturing and Industry 4.0. International Journal of Engineering and Manufacturing (IJEM), 2016. 6(4): p. 1-8.

20. M. Rylnikova, D. Radchenko, and D. Klebanov. Intelligent Mining Engineering Systems in the Structure of Industry 4.0. in E3S Web of Conferences. 2017. EDP Sciences.

21. Li, Y. and Z. Guanzeng, Thinking about Digital Technique Development of Construction Industry. Construction Economy, 2009: p. S1.

22. W.S. Alaloul, M.S. Liew, and N. Zawawi. Coordination process in construction projects management. in Engineering Challenges for Sustainable Future: Proceedings of the 3rd International Conference on Civil, Offshore and Environmental Engineering (ICCOEE 2016, Malaysia, 15-17 Aug 2016). 2016. CRC Press.

23. F. Khosrowshahi and Y. Arayici, Roadmap for implementation of BIM in the UK construction industry. Engineering, Construction and Architectural Management, 2012. 19(6): p. 610-635.

24. S. Azhar, Building information modeling (BIM): Trends, benefits, risks, and challenges for the AEC industry. Leadership and management in engineering, 2011. 11(3): p. 241-252.

25. S. Mihindu and Y. Arayici. Digital construction through BIM systems will drive the re-engineering of construction business practices. in Visualisation, 2008 International Conference. 2008. IEEE.

26. W.S. Alaloul, M.S. Liew, and N.A.B. Zawawi. A Framework for Coordination Process into Construction Projects. in MATEC Web of Conferences. 2016. EDP Sciences.

27. C. Merschbrock and B.E. Munkvold, Effective digital collaboration in the construction industry-A case study of BIM deployment in a hospital construction project. Computers in Industry, 2015. 73: p. 1-7.

28. A. Sattineni and R.H. Bradford, Estimating with BIM: A survey of US construction companies. Proceedings of the 28th ISARC, Seoul, Korea, 2011: p. 564-569.

29. W.S. Alaloul, M.S. Liew, and N.A.W. Zawawi. Communication, coordination and cooperation in construction projects: business environment and human behaviours. in IOP Conference Series: Materials Science and Engineering. 2017. IOP Publishing.

30. B. Becerik-Gerber, et al., Application areas and data requirements for BIM-enabled facilities management. Journal of construction engineering and management, 2011. 138(3): p. 431-442.

31. W. Alaloul, M. Liew, and N. Zawawi. Attributes of coordination process in construction projects. in Engineering Challenges for Sustainable Future: Proceedings of the 3rd International Conference on Civil, Offshore and Environmental Engineering (ICCOEE 2016, Malaysia, 15-17 Aug 2016). 2016. CRC Press. 